Article

\title{
Structural and Mechanical Properties of AlCoCrNi High Entropy Nitride Films: Influence of Process Pressure
}

\author{
Young Seok Kim ${ }^{\dagger}$, Hae Jin Park ${ }^{\dagger}$, Ki Seong Lim ${ }^{\mathbb{D}}$, Sung Hwan Hong ${ }^{\mathbb{D}}$ and Ki Buem Kim *D \\ Hibrid Materials Center (HMC), Department of Nanotechnology and Advanced Materials Engineering, \\ Sejong University, Seoul 05006, Korea; ysgim82@gmail.com (Y.S.K.); echo727@naver.com (H.J.P.); \\ limgs78@hanmail.net (K.S.L.); shhong@sejong.ac.kr (S.H.H.) \\ * Correspondence: kbkim@sejong.ac.kr \\ † These authors (Young Seok Kim and Hae Jin Park) contribute equally to this work.
}

Received: 24 November 2019; Accepted: 18 December 2019; Published: 21 December 2019

\begin{abstract}
In the present study, novel AlCoCrNi high entropy nitride (HEN) films were deposited on Si substrate by a reactive direct current magnetron sputtering system. In order to investigate the influence of sputtering parameters on the microstructure and mechanical properties of the film, nitrogen flow ratio $\left(\mathrm{R}_{\mathrm{N}}: 25-100 \%\right)$ and process pressure $\left(1.33 \times 10^{-1}-1.33 \mathrm{~Pa}\right)$ were controlled, respectively. All the films were identified as an amorphous phase with composition of near equiatomic ratios, regardless of the conditions of nitrogen flow ratios and process pressures. However, the limited mechanical properties were found for the films deposited under different nitrogen flow ratios with retaining the process pressure of $1.33 \mathrm{~Pa}$. To enhance the mechanical properties of the AlCoCrNi HEN film, process pressure was adjusted. From the transmission electron microscopy (TEM) observation, the structure of the film deposited at the process pressure of $1.33 \mathrm{~Pa}$ is identified as a porous and open structure with a number of density-deficient boundary and nano-scale voids. On the other hand, densified morphology of the film was observed at pressure of $1.33 \times 10^{-1} \mathrm{~Pa}$. As a result, the hardness, elastic modulus, and H/E were improved up to $16.8,243 \mathrm{GPa}$, and 0.0692 , respectively.
\end{abstract}

Keywords: high entropy nitrides; thin films; amorphous; process pressure; mechanical properties

\section{Introduction}

In 2004, Cantor et al. and Yeh et al. proposed a new alloy design concept called high-entropy alloys (HEAs), which is composed of multiple major elements in equiatomic or near equiatomic ratios. [1,2]. The basic idea of HEAs leads to high mixing entropy, sluggish diffusion, and severe lattice distortion, which tend to form the solid-solution phases rather than intermetallic compounds [3-5]. For those reasons, novel HEAs exhibit special and outstanding properties, such as high hardness and strength, high corrosion and wear resistance, and characteristic electrical properties [6-10]. It has been extensively studied for potential application in diverse areas, such as hard coatings, and diffusion barriers [11-18].

Specifically, in order to improve mechanical properties and oxidation resistance of the metal substrate in hard coating community, the film deposition for HEAs has been applied using the magnetron sputtering process [19-22]. It is known to be effective in optimizing the microstructure and mechanical properties of HEA and high entropy nitride (HEN) films by controlling the process parameters, such as sputtering power, substrate temperature, reactive gas flow ratio, and process pressure [23-25]. Especially, controlling the reactive gas $\left(\mathrm{N}_{2}\right.$ or $\left.\mathrm{O}_{2}\right)$ flow ratio can easily produce various high entropy nitride (or oxide) films $[26,27]$. It has been reported that $C h e n$ at al. has deposited 
an amorphous (FeCoNiCrCuAlMn)N HEN film, which exhibits maximum hardness of 11.8 GPa [28]. Furthermore, the structural quality of thin films deposited at low temperature is strongly affected by the process pressure, which establishes the mechanical properties of the films despite the formation of same phases $[29,30]$. For instance, Tsai et al. successfully fabricated dense and smooth TiZrHf multicomponent nitride films by adjusting the process pressure [31].

In a previous study, Jumaev et al. developed quaternary AlCoCrNi high entropy alloy fabricated by the arc-melting method, which exhibits the high strength and plasticity at wide temperature ranges [32]. The remarkable mechanical properties of the AlCoCrNi HEA provide promising potential for films applications. Based on the previous study, the AlCoCrNi HEA was selected as a target of sputtering deposition. The aim of present study is to optimize the sputtering parameters for the AlCoCrNi HEN system. To understand the effect of sputtering parameters on the microstructure and mechanical properties of the AlCoCrNi HEN films, the nitrogen flow ratio and process pressure were systematically controlled.

\section{Experimental}

AlCoCrNi high entropy nitride films on $\mathrm{Si}(100)$ wafer were fabricated in a reactive direct current (D.C.) magnetron sputtering system with high vacuum (KVS-4006L, Korea vacuum tech. Gimpo-si, Republic of Korea). The Si wafer was chosen for the investigation of the structural and mechanical properties of the thin films because of thin thickness and flat surface of substrate. The target with a dimension of $101.6 \mathrm{~mm}$ and thickness of $6.35 \mathrm{~mm}$, which was synthesized by powder metallurgy, was produced from Plansee SE. As a preliminary process, the Si substrates were rinsed with acetone, ethanol, and distilled water. The base pressure below $3.33 \times 10^{-4} \mathrm{~Pa}$ was maintained before the mixture gas of $\mathrm{Ar}$ and $\mathrm{N}_{2}$ was allowed into the vacuum chamber. In the previous study, we have reported that the high sputtering power (such as $300 \mathrm{~W}$ ) is an important factor to achieve the high entropy thin films utilizing the multi element target fabricated by powder metallurgy. Pre-sputtering process under Ar atmosphere was conducted at D.C. power of $300 \mathrm{~W}$ for $10 \mathrm{~min}$. A sputtering power was constantly retained at D.C. $300 \mathrm{~W}$ and total gas flow $\left(\mathrm{Ar}+\mathrm{N}_{2}\right)$ was controlled on 20 standard cubic centimeter per minute $(S C C M)$. During the deposition process, the nitrogen flow ratios $\left(R_{N}=N_{2} /\left[A r+N_{2}\right]\right)$ were varied from $25 \%$ to $100 \%$ and the process pressures were controlled from $1.33 \times 10^{-1} \mathrm{~Pa}$ to $1.33 \mathrm{~Pa}$. To reliably evaluate the mechanical properties, the thickness of the films was endeavored to set above $1 \mu \mathrm{m}$. The rotation speed of the substrate stage was 10 revolutions per minute. The present conditions for the deposition of the AlCoCrNi HEN films are summarized in Table 1.

Table 1. Deposition parameters of the AlCoCrNi high entropy nitride (HEN) films.

\begin{tabular}{ccc}
\hline Parameters & $\begin{array}{c}\text { Conditions of } \\
\text { Nitrogen Flow Ratio }\end{array}$ & Conditions of Process Pressure \\
\hline Nitrogen flow ratio, $\mathrm{R}_{\mathrm{N}}(\%)$ & $25,50,75$, and 100 & 25 \\
Process pressure $(\mathrm{Pa})$ & 10 & $1.33 \times 10^{-1}, 3.33 \times 10^{-1}, 6.67 \times 10^{-1}$, and 1.33 \\
Total gas flow $(\mathrm{SCCM})$ & & 20 \\
Base pressure $(\mathrm{Pa})$ & $<3.33 \times 10^{-4}$ \\
Sputtering power $(\mathrm{W})$ & D.C. 300 \\
Rotation speed $(\mathrm{rpm})$ & 10 \\
Deposition temperature & Room temperature \\
\hline
\end{tabular}

The thickness from the cross-section and relative chemical composition of the AlCoCrNi HEN films were determined by field-emission scanning-electron microscope (S-4700, Hitachi, Tokyo, Japan) with energy-dispersive X-ray spectroscope (EDS). The thickness obtained from the cross-sectional images and EDS measurements were determined at least for five times to ensure reliability, respectively. The deposition rate was calculated by dividing the film thickness by the deposition time. A structural analysis of the films was examined using X-ray diffractometer (Empyrean, Malvern Panalytical, Malvern, UK) with $\mathrm{Cu} \mathrm{K} \alpha 1$ radiation $(\lambda=1.5406 \AA)$. For the TEM analysis of AlCoCrNi HEN films, 
focus ion beam thinning (Helios NanoLab 600, FEI, Hillsboro, USA) was conducted with $\mathrm{Ga}^{+}$ions. A transmission electron microscope spectroscope (TecnaiF20, FEI, Hillsboro, USA) was employed to specifically investigate the microstructure of the films. The mechanical properties were measured by using a nanoindenter (NHT-X, CSM, Needham, USA) at room temperature. During the tests, indenter displacement was controlled to about $1 / 10$ of the film thickness, which could reliably evaluate the properties of the AlCoCrNi HEN films [33]. The indentation depth control mode was used to obtain the load-displacement curves and loading and unloading rates were controlled with $10 \mathrm{mN} / \mathrm{m}$. The hardness and elastic modulus were derived from the Oliver-Pharr method and then the ratio of hardness and elastic modulus (H/E) was calculated [34]. Despite being empirically calculated, the value of $\mathrm{H} / \mathrm{E}$ is used to provide some information of mechanical property, such as the fracture toughness of films [35]. The indentation tests for each sample were conducted at least 20 times and the average values excluding the maximum and minimum values were obtained.

\section{Results and Discussion}

\subsection{Effect of Nitrogen Flow Ratio}

Figure 1 displays the deposition rate of the AlCoCrNi nitride films, according to the nitrogen flow ratio $\left(R_{N}\right)$. The AlCoCrNi nitride film deposited at $R_{N}$ of $25 \%$ exhibits the deposition rate of $15.9 \pm 0.6 \mathrm{~nm} / \mathrm{nm}$. As the nitrogen flow ratio increases step-by-step, the deposition rate of the films accordingly decreases to $10.8 \pm 0.3 \mathrm{~nm} / \mathrm{min}$ for $R_{N}$ of $50 \%$, to $8.3 \pm 0.2 \mathrm{~nm} / \mathrm{min}$ for $R_{N}$ of $75 \%$, and to $6.3 \pm 0.2 \mathrm{~nm} / \mathrm{min}$ for $R_{N}$ of $100 \%$, respectively. The reduction in deposition rate can be probably attributed to target poisoning phenomenon which can be formation of nitride on the surface of metal target [36]. Moreover, the sputtering efficiency of reactive gas ions, such as nitrogen, have lower as compared with that of inert ions, such as argon [37]. Therefore, the deposition rate of AlCoCrNi nitride film decreases with increasing $R_{N}$ during the reactive sputtering process.

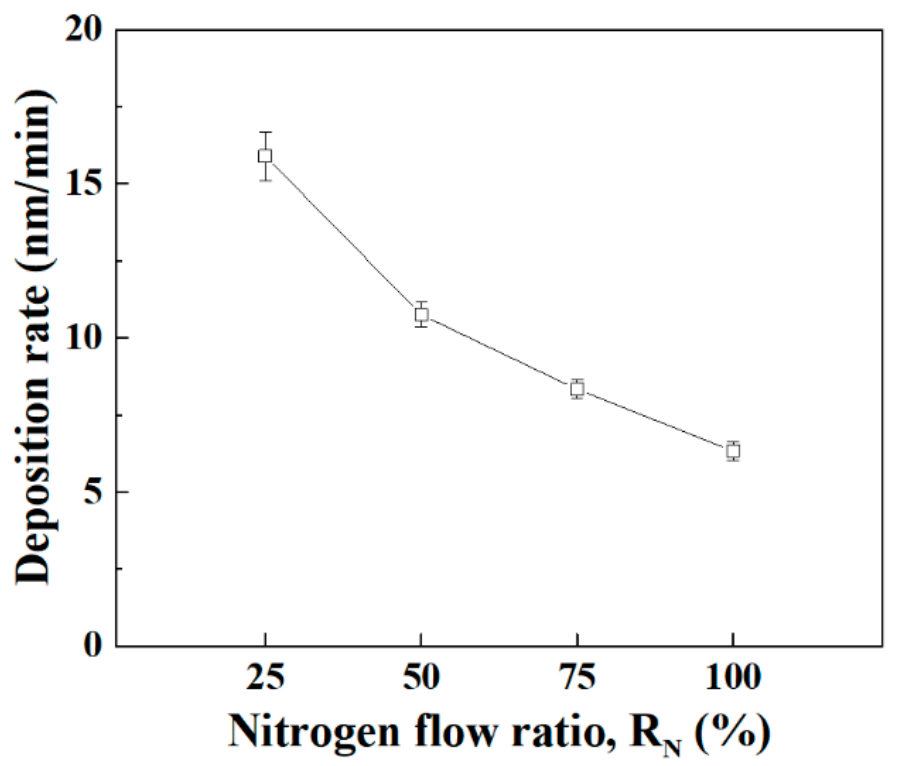

Figure 1. Deposition rate of the AlCoCrNi HEN films deposited under various nitrogen flow ratios, $\mathrm{R}_{\mathrm{N}}(\%)$.

Figure 2 shows the relative chemical compositions of the AlCoCrNi nitride films deposited at various nitrogen flow ratios $\left(R_{N}\right)$, obtained from SEM energy-dispersive $X$-ray spectroscopy (EDS). For all the nitride films deposited under various $R_{N}$ conditions, the relative concentration between the metallic elements was rather close to equiatomic ratios, regardless of $R_{N}$ variation. As $R_{N}$ increases from $25 \%$ to $100 \%$, it is identified that the concentration of nitrogen element in the films is contained 
from 20.0 to 38.3 at $\%$. On the other hand, it is clearly observed that all the nitride films contain high amount of oxygen element over $10 \mathrm{at} \%$, irrespective of $R_{N}$ conditions. The occurrence of unforeseen oxygen content in the films during sputtering process has been rarely discussed in previous studies, and the effect of a large amount of oxygen contamination on structure and mechanical properties will be discussed in Section 3.2.

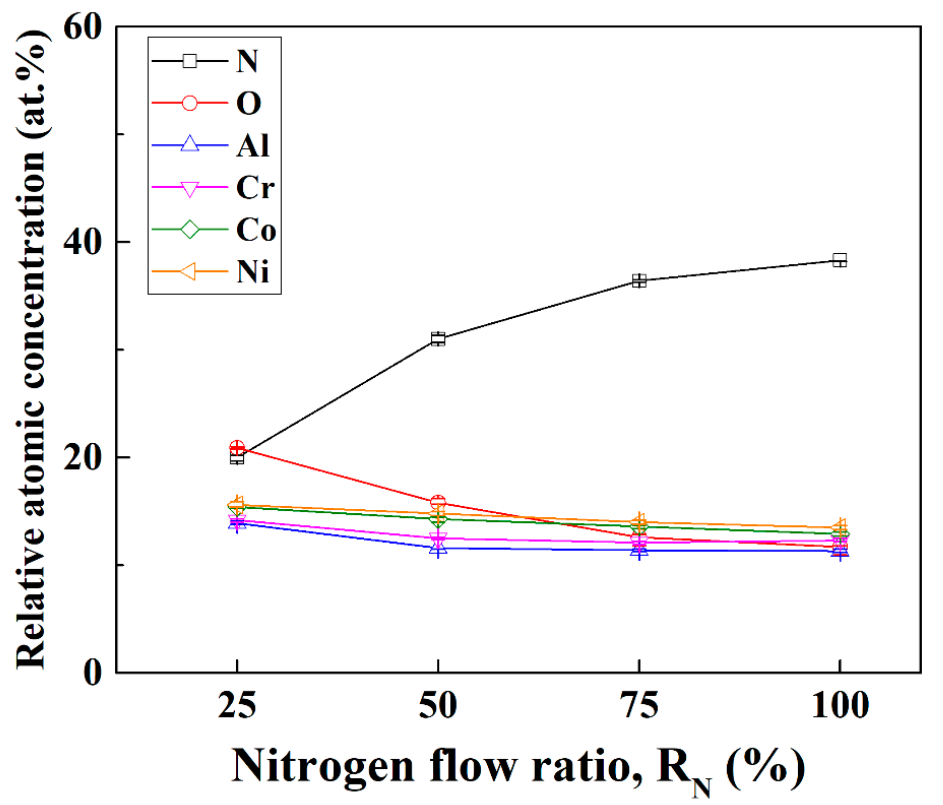

Figure 2. Relative chemical composition of the AlCoCrNi HEN films deposited under various nitrogen flow ratios.

Figure 3 shows the X-ray diffraction (XRD) patterns of AlCoCrNi HEN films deposited at various $R_{N}$. The XRD result of the Si substrate is also added, because of the thin thickness of the film inducing the inclusion of the structural information of the Si substrate. All the XRD patterns are identified as the broad halo pattern. These results indicate that the AlCoCrNi HEN film has a distinct tendency to form an amorphous structure at the present conditions of $\mathrm{R}_{\mathrm{N}}(25-100 \%)$. Generally, high mixing entropy and kinetic effect could affect the formation of the amorphous phase in the HEA or HEN film. The high mixing entropy effect could improve the mutual solubility between the constituent elements and suppress the formation of the crystalline structure [25]. Moreover, the rapid quenching effect during the sputtering deposition could effectively restrain the chemical fluctuation and suppression of crystallization [38]. With increasing $R_{N}$ up to $100 \%$, the center of the wide broad peak is shifted toward lower angles and intensity is decreased, gradually. The shift to lower angles of XRD peak relate with increased incorporation of nitrogen atoms in the amorphous structure, as the $R_{N}$ is gradually increased. Moreover, an increment of incorporation of nitrogen atoms gives rise to an indication of increase of the degree of structural disorder [39].

To evaluate hardness $\left(\mathrm{H}_{\mathrm{IT}}\right)$, elastic modulus $\left(\mathrm{E}_{\mathrm{IT}}\right)$ and $\mathrm{H} / \mathrm{E}$ of the AlCoCrNi HEN films deposited under different $\mathrm{R}_{\mathrm{N}}$, nanoindentation tests were conducted. The mechanical properties of the films are summarized in Table 2. For the AlCoCrNi HEN film with $R_{N}$ of $25 \%$, the hardness, elastic modulus, and $\mathrm{H} / \mathrm{E}$ are measured as $8.2 \pm 0.9,142 \pm 11 \mathrm{GPa}$, and $0.0577 \pm 0.0018$, respectively. It is observed that the values of hardness and elastic modulus on the AlCoCrNi HEN films with amorphous phase reveal similar characteristic, regardless of $R_{N}$ conditions. For the film deposited with $R_{N}$ of $100 \%$, it is not possible to obtain a reliable mechanical properties because it has insufficient film thickness caused by the target poisoning phenomenon and the lower sputtering efficiency. Under the present conditions of $\mathrm{R}_{\mathrm{N}}$, all the deposited AlCoCrNi HEN films reveal limited mechanical properties compared with other HEN films $[25,28,40]$. It has been reported that high oxygen contamination in the films deposited at 
high process pressure could result in inferior mechanical properties caused by the low film quality [31]. In order to enhance the mechanical properties of AlCoCrNi HEN film, the process pressure was controlled at a constant nitrogen flow ratio $\left(R_{N}=25 \%\right)$.

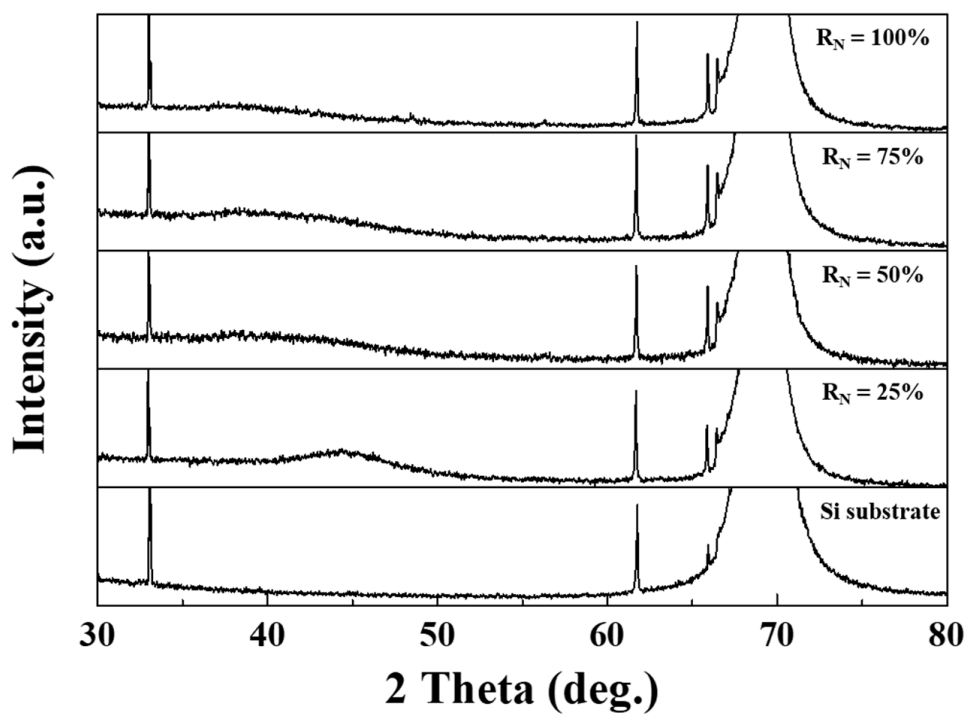

Figure 3. X-ray diffraction (XRD) patterns of the AlCoCrNi HEN films deposited under various nitrogen flow ratios.

Table 2. Hardness, elastic modulus and H/E of the AlCoCrNi HEN films according to the different nitrogen flow ratios.

\begin{tabular}{ccccc}
\hline \multirow{2}{*}{ Process Pressure (Pa) } & Nitrogen Flow Ratio, $\mathbf{R}_{\mathbf{N}} \mathbf{( \% )}$ & \multicolumn{3}{c}{ Mechanical Properties } \\
\cline { 3 - 5 } & & $\mathbf{H}_{\text {IT }} \mathbf{( G P a )}$ & $\mathbf{E}_{\text {IT }}(\mathbf{G P a})$ & $\mathbf{H} / \mathbf{E}$ \\
\hline \multirow{2}{*}{1.33} & 50 & $8.2 \pm 0.9$ & $142 \pm 11$ & $0.0577 \pm 0.0018$ \\
& 75 & $7.7 \pm 1.6$ & $146 \pm 20$ & $0.0527 \pm 0.0036$ \\
& 100 & $7.7 \pm 0.5$ & $146 \pm 18$ & $0.0527 \pm 0.0028$ \\
\hline
\end{tabular}

\subsection{Effect of Process Pressure}

Figure 4 displays the deposition rate of the AlCoCrNi HEN films deposited under different process pressures while retaining constant $\mathrm{R}_{\mathrm{N}}$ of $25 \%$. The HEN film deposited at the process pressure of $1.33 \times 10^{-1} \mathrm{~Pa}$ exhibits $17.9 \pm 0.4 \mathrm{~nm} / \mathrm{min}$, as observed in Figure 4 . With a rise of the process pressure to $1.33 \mathrm{~Pa}$, it is observed that the deposition rate of the films slightly decreases to $15.9 \pm 0.6 \mathrm{~nm} / \mathrm{min}$, except for the process pressure condition of $3.33 \times 10^{-1} \mathrm{~Pa}$ (deposition rate of $18.9 \pm 0.8 \mathrm{~nm} / \mathrm{min}$ ). This trend in which the deposition rate is decreased with a raise of process pressure is explained, as follows. First, the emitted atoms from the surface on the target undergo many collisions with the process gases in the chamber, such as argon and nitrogen, when the process pressure is increased from $1.33 \times 10^{-1}$ to $1.33 \mathrm{~Pa}$. The increased collisions between the emitted atoms and process gases result in the reduction of the mean free path which is the average travel distance of the emitted atoms before a collision. As a result, the sputtering yields decrease because of the scattering of sputtering atoms, and thus the deposition rate is decreased [30]. Second, the scattering effect leads to the energy transfer from the emitted atoms to the process gases (Ar or $\mathrm{N}_{2}$ ), which is called thermalization. Therefore, the energy loss of the emitted atoms also results in the reduction of the deposition rate [41]. Consequently, a higher deposition rate can be achieved at low process pressure. However, it should be noted that the deposition rate is not changed significantly while the process pressure is reduced to $1.33 \times 10^{-1} \mathrm{~Pa}$. It can be plausibly explained by introducing structure zone model which well-established the relation between the microstructure of the thin film and the most prominent deposition parameters [29,42]. 
According to structure zone model, the emitted atoms from the surface on the target are deposited to substrate with high energy at low process pressure, and those arriving atoms on the substrate possess high adatoms mobility. Therefore, the microstructure of the AlCoCrNi HEN film could reveal a denser, as compared with high process pressure. Based on these results, it could be inferred that the process pressure plays an important role on the structure of the deposited film.

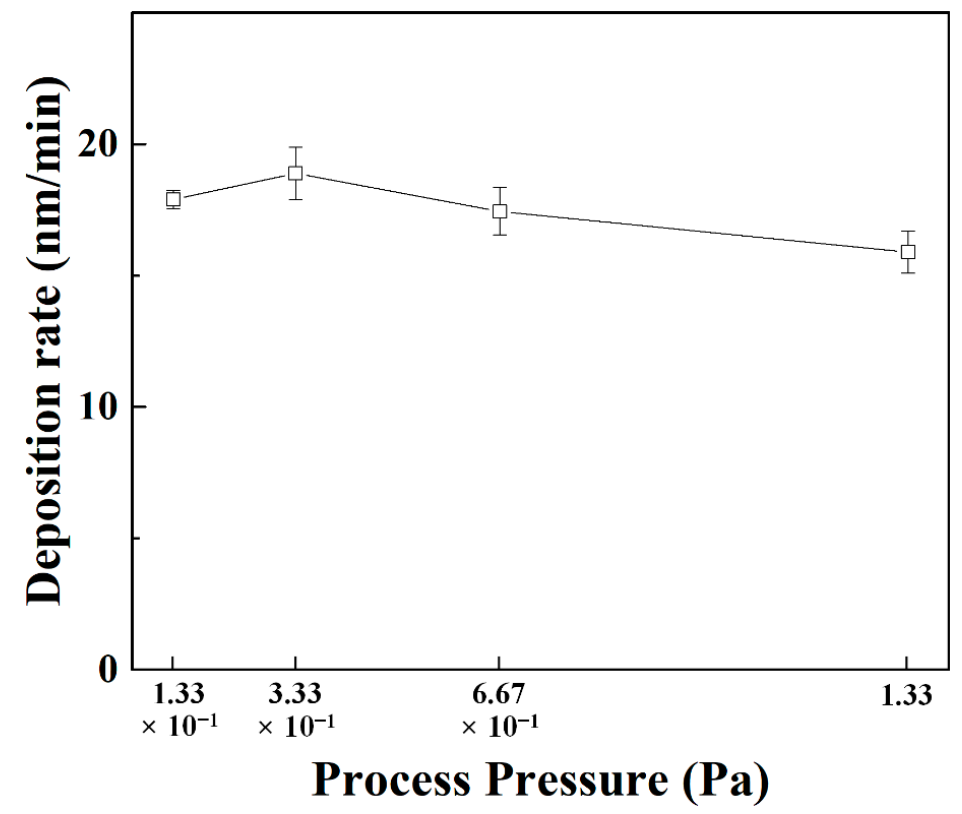

Figure 4. Deposition rate of the $\mathrm{AlCoCrNi} \mathrm{HEN} \mathrm{films} \mathrm{deposited} \mathrm{under} \mathrm{various} \mathrm{process} \mathrm{pressures} \mathrm{(Pa).}$

Figure 5 illustrates the relative chemical compositions of the AlCoCrNi HEN films under various process pressures, as obtained from EDS quantitative analysis. The near equiatomic ratios of the metallic elements are achieved at all the present process pressure conditions. As the process pressure is decreased to $1.33 \times 10^{-1} \mathrm{~Pa}$, the content of oxygen element which is regarded as impurity during the nitride deposition process be considerably influenced by the process pressure condition. Specifically, at the low process pressures of 3.33 and $1.33 \times 10^{-1} \mathrm{~Pa}$, the oxygen content is detected in $1.9 \pm 0.3 \%$ and $0.7 \pm 0.2 \%$, respectively. This result can be explained by a reduction in probability of impurity incorporation. Generally, the sputtered atoms at low pressure have a longer mean free path during the travel to the substrate, because of the decrease of the collisions with the process gases ( $\mathrm{Ar}$ or $\mathrm{N}_{2}$ ) and develop a dense microstructure caused by the high adatoms mobility [29,31]. On the other hand, the high process pressure during sputtering causes an increase in the collision between the sputtered atoms and process gases in the chamber, and results in the decrease of the mean free path. The low mobility of adatoms caused by the decrease of the mean free path lead to a less dense microstructure (porous and open structure). Consequently, a large amount of the oxygen contamination could be induced in the porous and open structure when the deposited film is exposed to the atmosphere after process [43]. Based on the deposition rate and composition analysis, it can be deduced that controlling a process pressure during the sputtering deposition plays an important role in density and the purity of the AlCoCrNi HEN film.

Figure 6 shows the XRD patterns of the AlCoCrNi HEN films deposited under various process pressures, inclusive of the information of the Si substrate. All the XRD patterns are identified as the broad halo pattern between $40^{\circ}$ and $47^{\circ}$. The non-shift of the center of the broad peak is observed because the films contain similar level of nitrogen concentration $(20.0 \pm 0.3-21.7 \pm 0.6$ at \%) at the present conditions. It is obvious that all the AlCoCrNi HEN films tend to strongly give rise to the formation of an amorphous structure at the present process pressures from $1.33 \times 10^{-1}$ to $1.33 \mathrm{~Pa}$, in common with the conditions of nitrogen flow ratio $(25-100 \%)$. 


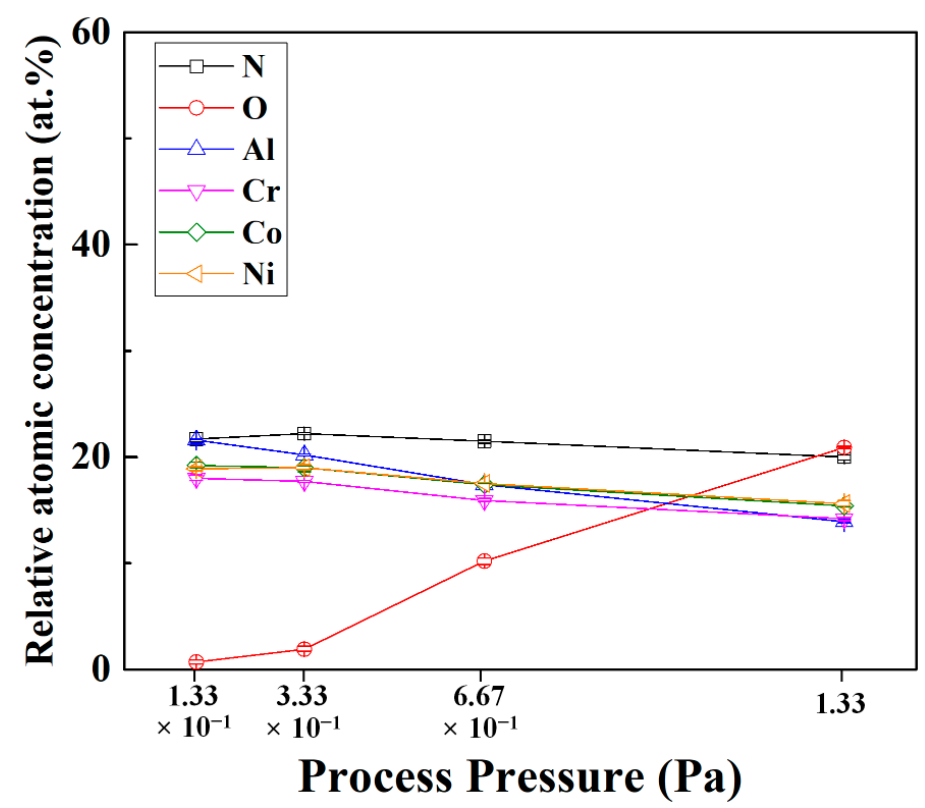

Figure 5. Relative chemical composition of the AlCoCrNi HEN films deposited under various process pressures $(\mathrm{Pa})$.

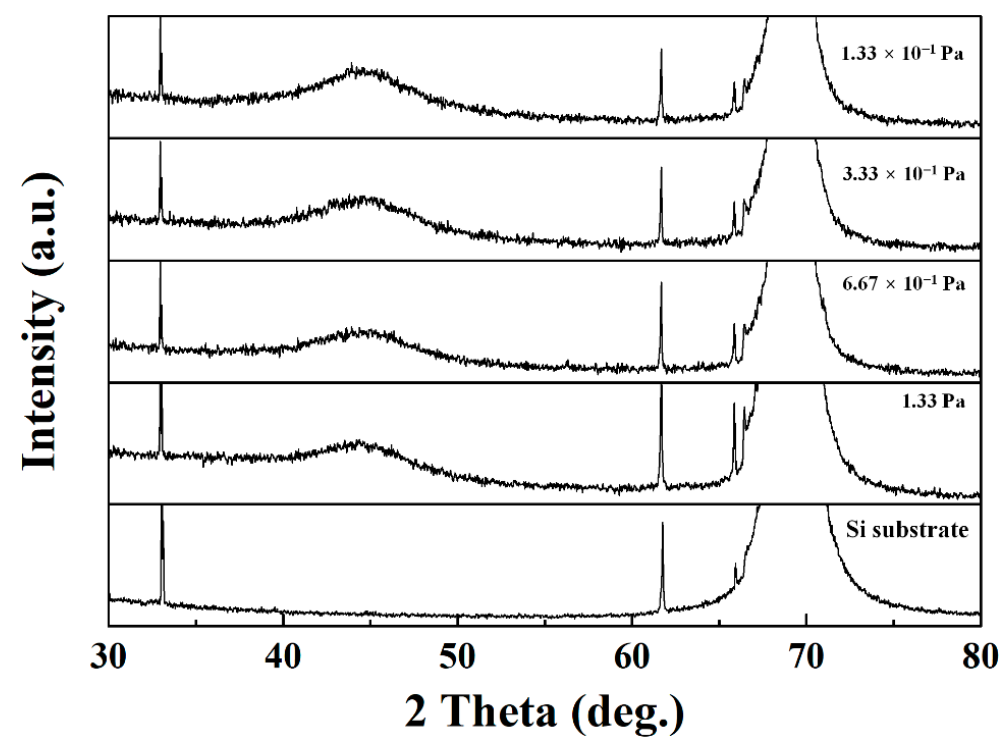

Figure 6. XRD patterns of the AlCoCrNi HEN films deposited at various process pressures (Pa).

For the detailed microstructural analysis, a transmission electron microscopy (TEM) analysis was conducted on the AlCoCrNi HEN films. Figure 7a presents the bright-field (BF) image with inset of selected area electron diffraction (SAED) patterns of the AlCoCrNi HEN film deposited at the process pressure of $1.33 \mathrm{~Pa}$. A thickness of the film is measured to be $1470 \mathrm{~nm}$. From the two SAED patterns acquired from the region (i) and region (ii), a diffuse hallow ring pattern is observed, which implies the formation of a homogeneous amorphous phase. Additionally, any crystalline phases are not observed, as shown high-resolution (HR) image of Figure $7 \mathrm{~b}$. These results of TEM analysis are consonant with previous XRD result in Figure 6. A detailed investigation of the structure of the film in Figure 7a,c reveal porous and open structure with a number of density-deficient boundary and nano-scale voids along with the growth direction, similar to the observation of the previous study [44]. As mentioned in Figure 5, the porous and open structure could include a large amount of the oxygen contamination in EDS measurement. Figure $7 \mathrm{~d}$ shows the BF image of AlCoCrNi HEN film at the process pressure of $1.33 \times 10^{-1} \mathrm{~Pa}$, corresponding with inset of two SAED patterns. The featureless morphology is 
observed with a thickness of $1630 \mathrm{~nm}$. The corresponding SAED patterns, acquired from the region (iii) and region (iv) in Figure 7d, also reveal a diffuse hallow ring pattern which suggests that the amorphous phase is similar to that observed in Figure 7a. It is also observed that the HEN film deposited at the $1.33 \times 10^{-1} \mathrm{~Pa}$ is in fully amorphous phase, as shown in Figure 6. However, the structure of AlCoCrNi HEN film deposited at $1.33 \times 10^{-1} \mathrm{~Pa}$ is clearly observed with densified structure than the deposition condition of $1.33 \mathrm{~Pa}$, as shown in Figure 7f. It is supposed that the structural difference of the HEN films, deposited at the 1.33 and $1.33 \times 10^{-1} \mathrm{~Pa}$, may affect the mechanical properties.
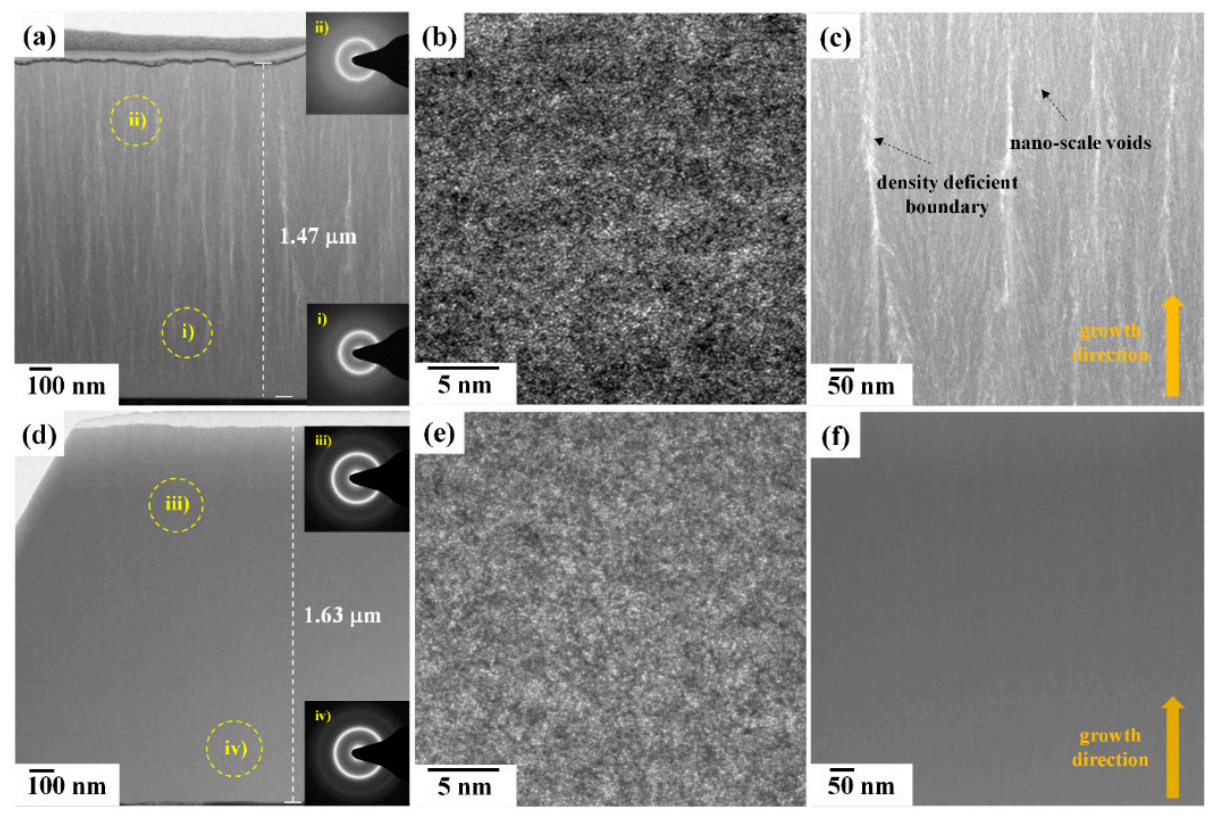

Figure 7. (a-c) Bright-field (BF) and high-resolution (HR) images of the AlCoCrNi HEN film deposited at process pressure of $1.33 \mathrm{~Pa}$. (d-f) $\mathrm{BF}$ and $\mathrm{HR}$ images of the $\mathrm{AlCoCrNi} \mathrm{HEN}$ film deposited at process pressure of $1.33 \times 10^{-1} \mathrm{~Pa}$, and the corresponding SAED patterns obtained from region (i-iv) in Figure $7 \mathrm{a}, \mathrm{d}$, respectively.

Table 3 shows the hardness, elastic modulus, and H/E of the AlCoCrNi HEN films deposited under various process pressures from 1.33 and $1.33 \times 10^{-1} \mathrm{~Pa}$. For the HEN film with less dense amorphous structure including a number of density-deficient boundary and nano-scale voids (1.33 Pa), the hardness and elastic modulus are estimated as $8.2 \pm 0.9$ and $142 \pm 11 \mathrm{GPa}$, respectively. The limited mechanical properties of the film deposited at $1.33 \mathrm{~Pa}$ can be explained as follows. The sputtered atoms from the target at higher process pressures increase the probability of the collisions with gases. The scattering effect by the collisions can introduce more impurities (such as oxygen) from the chamber walls, and resulting in inclusion of a large amount of oxygen into the film. Moreover, the short mean free path by scattering effect lead to low adatoms mobility and then the structure of the thin film is formed to porous. In addition, the density-deficient boundary along the growth direction of the thin film is grown up to the surface of top as shown in Figure 7a. It is believed that a large amount of oxygen in the film is incorporated into the porous and open structure, exposing to the atmosphere after process. Hence, a number of density-deficient boundaries and voids, which cause the decrease in density of films, result in considerably reduced hardness. The similar result that studied the relationship between density and hardness of the films, are reported by Tsai et al. [31]. As the process pressure decreases with retaining the $\mathrm{R}_{\mathrm{N}}$ of $25 \%$, the hardness and elastic modulus progressively increases to $11.9 \pm 0.8$ and $176 \pm 21 \mathrm{GPa}$ for $6.67 \times 10^{-1} \mathrm{~Pa}$, and $13.1 \pm 2.7$ and $193 \pm 19 \mathrm{GPa}$ for $3.33 \times 10^{-1} \mathrm{~Pa}$, as can be seen in Table 3. Furthermore, the highest mechanical properties of the present AlCoCrNi HEN films can be achieved at the process pressure condition of $1.33 \times 10^{-1} \mathrm{~Pa}$, which reveals the hardness of 
$16.8 \pm 0.5 \mathrm{GPa}$, and the elastic modulus of $243 \pm 39 \mathrm{GPa}$, respectively. The calculated $\mathrm{H} / \mathrm{E}$ ratios also increased from $0.0577 \pm 0.0018$ to $0.0692 \pm 0.0076$, with the decrease of process pressure.

Table 3. Hardness, elastic modulus and H/E of the AlCoCrNi HEN films deposited under the different process pressures.

\begin{tabular}{ccccc}
\hline \multirow{2}{*}{ Process Pressure (Pa) } & \multirow{2}{*}{ Nitrogen Flow Ratio, $\mathbf{R}_{\mathbf{N}} \mathbf{( \% )}$} & \multicolumn{3}{c}{ Mechanical Properties } \\
\cline { 3 - 5 } & & $\mathbf{H}_{\mathrm{IT}} \mathbf{( G P a )}$ & $\mathbf{E}_{\mathrm{IT}}(\mathbf{G P a})$ & $\mathbf{H} / \mathbf{E}$ \\
\hline 1.33 & 25 & $8.2 \pm 0.9$ & $142 \pm 11$ & $0.0577 \pm 0.0018$ \\
$6.67 \times 10^{-1}$ & & $11.9 \pm 0.8$ & $176 \pm 21$ & $0.0669 \pm 0.0027$ \\
$3.33 \times 10^{-1}$ & $13.1 \pm 2.7$ & $193 \pm 19$ & $0.0681 \pm 0.0072$ \\
$1.33 \times 10^{-1}$ & & $16.8 \pm 0.5$ & $243 \pm 39$ & $0.0692 \pm 0.0076$ \\
\hline
\end{tabular}

In present study, all the AlCoCrNi high entropy nitride films are identified as an amorphous phase, which is independent on the conditions of nitrogen flow ratio and process pressure. Nevertheless, the present $\mathrm{AlCoCrNi}$ HEN films reveal a tendency such that the mechanical properties are dependent on the conditions of process pressure. It could be supposed that the tendency is affected by the structural characteristic of the HEN films. For the process pressure of $1.33 \mathrm{~Pa}$, the AlCoCrNi HEN film shows porous and open amorphous structure with nano-scale voids and density deficient boundary because of low adatoms mobility caused by short mean free path of sputtered atoms and the less dense structure is in agreement with the zone 1 structure of Thornton model, as shown in Figure 8a [42]. Hence, it is believed that the AlCoCrNi HEN film deposited at high process pressure reveals limited mechanical properties. On the other hand, sputtered atoms possess enhanced mean free path resulting from the reduction of collisions with the gases $\left(\mathrm{Ar}\right.$ or $\mathrm{N}_{2}$ ) in the chamber when the film is deposited at low process pressure, as shown in Figure 8b [29]. As a result of enhanced adatoms mobility, the structure of the AlCoCrNi HEN film can be formation of densified amorphous structure. Consequently, it is believed that the densification of the structure on the AlCoCrNi HEN film leads to an increase of the mechanical properties, such as hardness, elastic modulus, and value of $\mathrm{H} / \mathrm{E}$. Based on these results, it is believed that the process pressure has a crucial role in controlling the morphology and mechanical properties of the AlCoCrNi HEN films with amorphous phase.

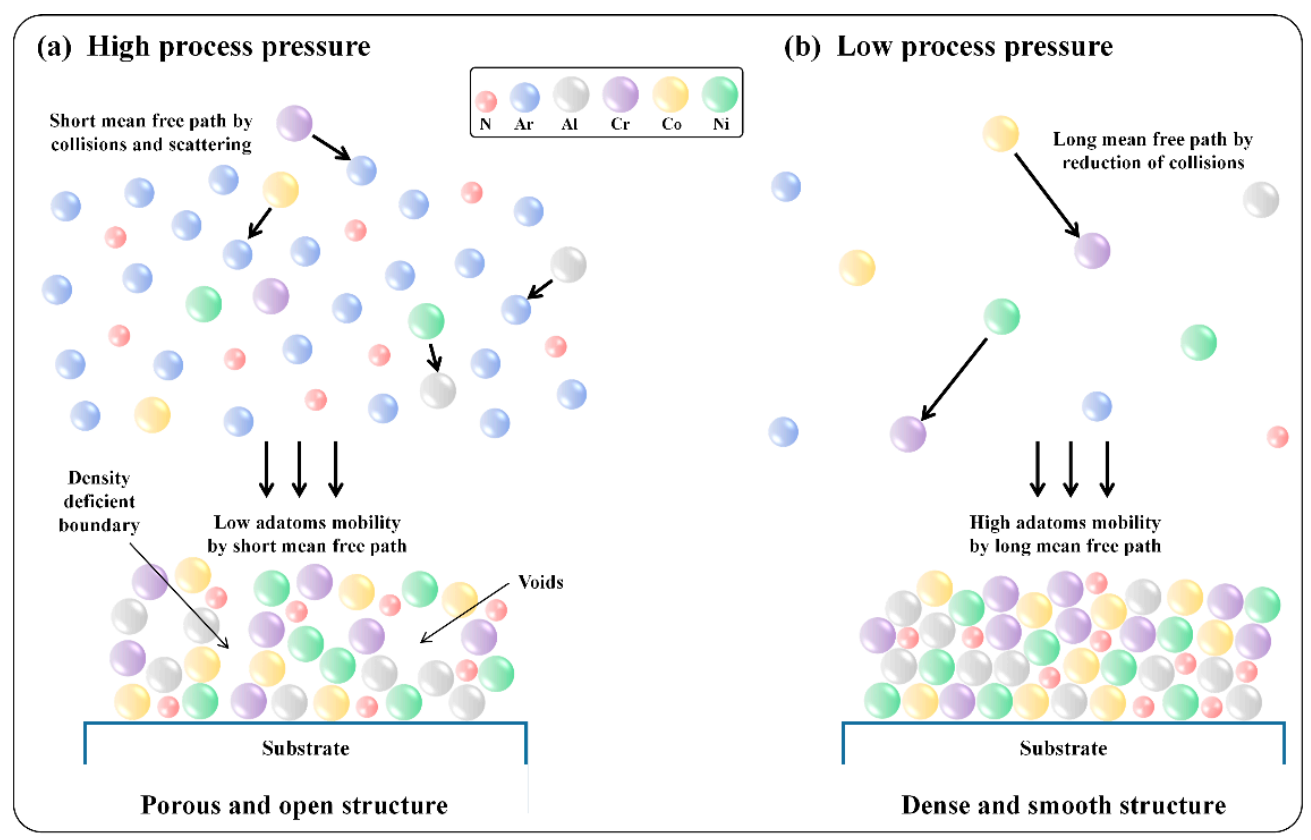

Figure 8. Schematic illustrations for the process pressure dependence of growth morphology on AlCoCrNi HEN films: (a) deposited at high process pressure; (b) deposited at low process pressure. 


\section{Conclusions}

$\mathrm{AlCoCrNi}$ high entropy nitride films were deposited on Si substrates by a reactive direct current magnetron sputtering system. In order to investigate the influence of sputtering parameters on the microstructure and mechanical properties of $\mathrm{AlCoCrNi} H E N$ film, nitrogen flow ratio $\left(\mathrm{R}_{\mathrm{N}}: 25-100 \%\right)$ and process pressure $\left(1.33 \times 10^{-1}-1.33 \mathrm{~Pa}\right)$ were controlled, respectively. All the AlCoCrNi HEN films were identified as an amorphous phase with composition of near equiatomic ratios, regardless of the conditions of nitrogen flow ratio and process pressure. However, the oxygen contamination in the films were found and the limited mechanical properties were observed to the AlCoCrNi HEN films deposited under various nitrogen flow ratios with a process pressure retained at $1.33 \mathrm{~Pa}$. To enhance the mechanical properties of $\mathrm{AlCoCrNi} \mathrm{HEN} \mathrm{film,} \mathrm{process} \mathrm{pressure} \mathrm{was} \mathrm{controlled} \mathrm{while} \mathrm{retaining}$ the $R_{N}$ at a constant $25 \%$. As the process pressure decreases from 1.33 to $1.33 \times 10^{-1} \mathrm{~Pa}$, the oxygen contamination was reduced from $20.9 \%$ to $0.7 \%$. From the TEM observation, the structure of the AlCoCrNi HEN film deposited at the process pressure of $1.33 \mathrm{~Pa}$ was revealed as porous and open amorphous structure with a number of density deficient boundary and nano-scale voids, which implied a low density of structure on the film. On the other hand, the densified morphology of the film was observed at process pressure of $1.33 \times 10^{-1} \mathrm{~Pa}$. As a result, the hardness, elastic modulus, and $\mathrm{H} / \mathrm{E}$ were improved up to $16.8 \mathrm{GPa}, 243 \mathrm{GPa}$, and 0.0692 , respectively.

Author Contributions: Y.S.K. and H.J.P. conducted the experimental measurements and analysis. The artwork was designed by K.S.L., H.J.P. and S.H.H. made discussions of the results. Y.S.K. wrote the paper. All processes were supervised by K.B.K. including the paper revision. All authors have read and agreed to the published version of the manuscript.

Funding: This work was supported by the Technology Innovation Program (Project No. 10063052, Development of advanced nano-micron coating material and coated cutting tool for Hard-to-Cut) funded By Ministry of Trade, Industry and Energy (MOTIE, Korea), the Basic Research Laboratory Program through the Ministry of Education of the Republic of Korea (2019R1A4A1026125), and the National Research Foundation of Korea (NRF) grant funded by the Korea government (MSIT) (No. 2018R1A2B3007167).

Conflicts of Interest: The authors declare no conflict of interest.

\section{References}

1. Cantor, B.; Chang, I.; Knight, P.; Vincent, A. Microstructural development in equiatomic multicomponent alloys. Mater. Sci. Eng. A 2004, 375, 213-218. [CrossRef]

2. Yeh, J.W.; Chen, S.K.; Lin, S.J.; Gan, J.Y.; Chin, T.S.; Shun, T.T.; Tsau, C.H.; Chang, S.Y. Nanostructured high-entropy alloys with multiple principal elements: Novel alloy design concepts and outcomes. Adv. Eng. Mater. 2004, 6, 299-303. [CrossRef]

3. Tong, C.J.; Chen, M.R.; Yeh, J.W.; Lin, S.J.; Chen, S.K.; Shun, T.T.; Chang, S.Y. Mechanical performance of the $\mathrm{Al}$ x CoCrCuFeNi high-entropy alloy system with multiprincipal elements. Metall. Mater. Trans. A 2005, 36, 1263-1271. [CrossRef]

4. Zhang, Y.; Zhou, Y.J.; Lin, J.P.; Chen, G.L.; Liaw, P.K. Solid-solution phase formation rules for multi-component alloys. Adv. Eng. Mater. 2008, 10, 534-538. [CrossRef]

5. George, E.P.; Raabe, D.; Ritchie, R.O. High-entropy alloys. Nat. Rev. Mater. 2019, 4, 515-534. [CrossRef]

6. Kim, H.; Nam, S.; Roh, A.; Son, M.; Ham, M.H.; Kim, J.H.; Choi, H. Mechanical and electrical properties of NbMoTaW refractory high-entropy alloy thin films. Int. J. Refract. Met. Hard Mater. 2019, 80, $286-291$. [CrossRef]

7. Gorr, B.; Müller, F.; Azim, M.; Christ, H.J.; Müller, T.; Chen,H.; Kauffmann, A.; Heilmaier, M. High-temperature oxidation behavior of refractory high-entropy alloys: Effect of alloy composition. Oxid. Met. 2017, 88, 339-349. [CrossRef]

8. Zhou, Y.; Zhang, Y.; Wang, Y.; Chen, G. Solid solution alloys of Al Co Cr Fe Ni Ti x with excellent room-temperature mechanical properties. Appl. Phys. Lett. 2007, 90, 181904. [CrossRef]

9. Huang, Y.S.; Chen, L.; Lui, H.W.; Cai, M.H.; Yeh, J.W. Microstructure, hardness, resistivity and thermal stability of sputtered oxide films of AlCoCrCu0. 5NiFe high-entropy alloy. Mater. Sci. Eng. A 2007, 457, 77-83. [CrossRef] 
10. Wu, J.M.; Lin, S.J.; Yeh, J.W.; Chen, S.K.; Huang, Y.S.; Chen, H.C. Adhesive wear behavior of AlxCoCrCuFeNi high-entropy alloys as a function of aluminum content. Wear 2006, 261, 513-519. [CrossRef]

11. Senkov, O.N.; Miracle, D.B.; Chaput, K.J.; Couzinie, J.P. Development and exploration of refractory high entropy alloys-A review. J. Mater. Res. 2018, 33, 3092-3128. [CrossRef]

12. Tsai, M.H.; Wang, C.W.; Lai, C.H.; Yeh, J.W.; Gan, J.Y. Thermally stable amorphous (Al Mo Nb Si Ta Ti V Zr) $50 \mathrm{~N} 50$ nitride film as diffusion barrier in copper metallization. Appl. Phys. Lett. 2008, 92, 052109. [CrossRef]

13. Raju, M.; Ananth, M.; Vijayaraghavan, L. Influence of temperature on the electrochemical characteristics of MmNi3. 03Si0. 85Co0. 60Mn0. 31Al0. 08 hydrogen storage alloys. J. Power Sources 2008, 180, 830-835. [CrossRef]

14. Ye, Q.; Feng, K.; Li, Z.; Lu, F.; Li, R.; Huang, J.; Wu, Y. Microstructure and corrosion properties of CrMnFeCoNi high entropy alloy coating. Appl. Surf. Sci. 2017, 396, 1420-1426. [CrossRef]

15. Malinovskis, P.; Fritze, S.; Riekehr, L.; von Fieandt, L.; Cedervall, J.; Rehnlund, D.; Nyholm, L.; Lewin, E.; Jansson, U. Synthesis and characterization of multicomponent (CrNbTaTiW) $\mathrm{C}$ films for increased hardness and corrosion resistance. Mater. Des. 2018, 149, 51-62. [CrossRef]

16. Hsieh, T.; Hsu, C.; Wu, C.; Kao, J.; Hsu, C. Effects of deposition parameters on the structure and mechanical properties of high-entropy alloy nitride films. Curr. Appl. Phys. 2018, 18, 512-518. [CrossRef]

17. Mayrhofer, P.H.; Kirnbauer, A.; Ertelthaler, P.; Koller, C.M. High-entropy ceramic thin films; A case study on transition metal diborides. Scr. Mater. 2018, 149, 93-97. [CrossRef]

18. Li, Y.; Kostka, A.; Savan, A.; Ludwig, A. Atomic-scale investigation of fast oxidation kinetics of nanocrystalline CrMnFeCoNi thin films. J. Alloys Compd. 2018, 766, 1080-1085. [CrossRef]

19. Dolique, V.; Thomann, A.L.; Brault, P.; Tessier, Y.; Gillon, P. Thermal stability of AlCoCrCuFeNi high entropy alloy thin films studied by in-situ XRD analysis. Surf. Coat. Technol. 2010, 204, 1989-1992. [CrossRef]

20. Liang, S.C.; Tsai, D.C.; Chang, Z.C.; Sung, H.S.; Lin, Y.C.; Yeh, Y.J.; Deng, M.J.; Shieu, F.S. Structural and mechanical properties of multi-element (TiVCrZrHf) $\mathrm{N}$ coatings by reactive magnetron sputtering. Appl. Surf. Sci. 2011, 258, 399-403. [CrossRef]

21. Feng, X.; Tang, G.; Sun, M.; Ma, X.; Wang, L. Chemical state and phase structure of (TaNbTiW) N films prepared by combined magnetron sputtering and PBII. Appl. Surf. Sci. 2013, 280, 388-393. [CrossRef]

22. Huang, P.K.; Yeh, J.W. Inhibition of grain coarsening up to $1000 \mathrm{C}$ in (AlCrNbSiTiV) N superhard coatings. Scr. Mater. 2010, 62, 105-108. [CrossRef]

23. Cheng, K.H.; Lai, C.H.; Lin, S.J.; Yeh, J.W. Structural and mechanical properties of multi-element (AlCrMoTaTiZr) Nx coatings by reactive magnetron sputtering. Thin Solid Films 2011, 519, 3185-3190. [CrossRef]

24. Lai, C.H.; Lin, S.J.; Yeh, J.W.; Chang, S.Y. Preparation and characterization of AlCrTaTiZr multi-element nitride coatings. Surf. Coat. Technol. 2006, 201, 3275-3280. [CrossRef]

25. Ren, B.; Shen, Z.; Liu, Z. Structure and mechanical properties of multi-element (AlCrMnMoNiZr) Nx coatings by reactive magnetron sputtering. J. Alloys Compd. 2013, 560, 171-176. [CrossRef]

26. Le, D.D.; Hong, S.K.; Ngo, T.S.; Lee, J.; Park, Y.C.; Hong, S.I.; Na, Y.S. Microstructural Investigation of CoCrFeMnNi High Entropy Alloy Oxynitride Films Prepared by Sputtering Using an Air Gas. Met. Mater. Int. 2018, 24, 1285-1292. [CrossRef]

27. Sheng, W.; Yang, X.; Wang, C.; Zhang, Y. Nano-crystallization of high-entropy amorphous NbTiAlSiWxNy films prepared by magnetron sputtering. Entropy 2016, 18, 226. [CrossRef]

28. Chen, T.; Shun, T.; Yeh, J.; Wong, M. Nanostructured nitride films of multi-element high-entropy alloys by reactive DC sputtering. Surf. Coat. Technol. 2004, 188, 193-200. [CrossRef]

29. Ellmer, K. Magnetron sputtering of transparent conductive zinc oxide: Relation between the sputtering parameters and the electronic properties. J. Phys. D 2000, 33, R17. [CrossRef]

30. Aissa, K.A.; Achour, A.; Camus, J.; Le Brizoual, L.; Jouan, P.Y.; Djouadi, M.A. Comparison of the structural properties and residual stress of AlN films deposited by dc magnetron sputtering and high power impulse magnetron sputtering at different working pressures. Thin Solid Films 2014, 550, 264-267. [CrossRef]

31. Tsai, D.C.; Chang, Z.C.; Kuo, B.H.; Chen, B.C.; Chen, E.C.; Shieu, F.S. Wide variation in the structure and physical properties of reactively sputtered (TiZrHf) N coatings under different working pressures. J. Alloys Compd. 2018, 750, 350-359. [CrossRef] 
32. Jumaev, E.; Hong, S.H.; Kim, J.T.; Park, H.J.; Kim, Y.S.; Mun, S.C.; Park, J.Y.; Song, G.; Lee, J.K.; Min, B.H. Chemical evolution-induced strengthening on AlCoCrNi dual-phase high-entropy alloy with high specific strength. J. Alloys Compd. 2019, 777, 828-834. [CrossRef]

33. Bull, S. Nanoindentation of coatings. J. Phys. D Appl. Phys. 2005, 38, R393. [CrossRef]

34. Pharr, G.; Oliver, W. Measurement of thin film mechanical properties using nanoindentation. Mrs Bull. 1992, 17, 28-33. [CrossRef]

35. Leyland, A.; Matthews, A. On the significance of the $\mathrm{H} / \mathrm{E}$ ratio in wear control: A nanocomposite coating approach to optimised tribological behaviour. Wear 2000, 246, 1-11. [CrossRef]

36. Jehn, H.A.; Hofmann, S.; Rückborn, V.E.; Münz, W.D. Morphology and properties of sputtered (Ti, Al) N layers on high speed steel substrates as a function of deposition temperature and sputtering atmosphere. J. Vac. Sci. Technol. A 1986, 4, 2701-2705. [CrossRef]

37. Mason, R.S.; Pichilingi, M. Sputtering in a glow discharge ion source-pressure dependence: Theory and experiment. J. Phys. D Appl. Phys. 1994, 27, 2363. [CrossRef]

38. An, Z.; Jia, H.; Wu, Y.; Rack, P.D.; Patchen, A.D.; Liu, Y.; Ren, Y.; Li, N.; Liaw, P.K. Solid-solution CrCoCuFeNi high-entropy alloy thin films synthesized by sputter deposition. Mater. Res. Lett. 2015, 3, 203-209. [CrossRef]

39. Ghidelli, M.; Gravier, S.; Blandin, J.J.; Pardoen, T.; Raskin, J.P.; Mompiou, F. Compositional-induced structural change in ZrxNi100 - $\mathrm{x}$ thin film metallic glasses. J. Alloys Compd. 2014, 615, S348-S351. [CrossRef]

40. Liu, L.; Zhu, J.; Hou, C.; Li, J.; Jiang, Q. Dense and smooth amorphous films of multicomponent FeCoNiCuVZrAl high-entropy alloy deposited by direct current magnetron sputtering. Mater. Des. 2013, 46, 675-679. [CrossRef]

41. Depla, D.; Leroy, W. Magnetron sputter deposition as visualized by Monte Carlo modeling. Thin Solid Films 2012, 520, 6337-6354. [CrossRef]

42. Thornton, J.A. The microstructure of sputter-deposited coatings. J. Vac. Sci. Technol. A. 1986, 4, 3059-3065. [CrossRef]

43. French, B.; Bilello, J. In situ observations of the real-time stress-evolution and delamination of thin Ta films on Si (100). Thin Solid Films 2004, 446, 91-98. [CrossRef]

44. Kim, Y.S.; Park, H.J.; Mun, S.C.; Jumaev, E.; Hong, S.H.; Song, G.; Kim, J.T.; Park, Y.K.; Kim, K.S.; Jeong, S.I. Investigation of structure and mechanical properties of TiZrHfNiCuCo high entropy alloy thin films synthesized by magnetron sputtering. J. Alloys Compd. 2019, 797, 834-841. [CrossRef]

(C) 2019 by the authors. Licensee MDPI, Basel, Switzerland. This article is an open access article distributed under the terms and conditions of the Creative Commons Attribution (CC BY) license (http://creativecommons.org/licenses/by/4.0/). 